\title{
Teaching Practices that Improve Student Learning: Five Experiential Approaches
}

\author{
Scott Wurdinger \\ Minnesota State University \\ Jennifer Rudolph \\ Minnesota State University
}

\begin{abstract}
University students are disengaged with learning. One reason is because educators continue to overuse the lecture format, which creates a situation where students engage in other tasks, such as sending text messages to their friends, instead of listening to the information being given by the instructor. If institutions and educators want to improve learning environments and increase retention rates, it is argued that they should consider embracing more active methods of learning that inspire and motivate students to learn. Five innovative teaching approaches discussed in this article include: project-based learning, problem-based learning, service learning, place-based education, and active learning. Practical considerations are provided to help educators understand how to use and apply these approaches. It is contended that using these five innovative practices at the university level will help inspire and motivate students to learn, resulting in more exciting classrooms and a better-educated society.
\end{abstract}

Imagine if you were totally free to do whatever you wanted in your classroom or learning environment. Imagine teaching without any confines-no mandated tests, no mandated assessment procedures, and no mandated system-wide rules to follow. You could use any materials and methods, and you concentrate on one thing: student learning. What would you do? What would you use for materials and how would you create an exciting learning environment where students could not wait to get to class?

Unfortunately, information delivery in classroom settings continues to rely on the lecture format as the dominant teaching approach because it is efficient in providing students with large amounts of information in short amounts of time. Students, however, become quickly disengaged when educators do most of the talking and do not allow them to actively participate in the classroom. While lecturing is necessary, its effectiveness may be limited. How much learning actually occurs when educators do all of the talking and do not provide opportunities for students to apply information?

Scott Wurdinger is a professor of experiential education and leadership studies and coordinator of the doctoral program in Educational Leadership at Minnesota State University, Mankato. Jennifer Rudolph is the Educational Advisor and Program Coordinator of the Educational Talent Search Program at Minnesota State University, Mankato. 
Listening to students tell their stories of how they were taught is discouraging because many of them were the recipients of passive methods of learning. The same theme seems to surface: remember this information for the next examination. When asked how they feel about such experiences they use terms such as "bored," "oppressed," "devalued,” and "ripped off.”

On the other hand, listening to them tell stories of when they were most engaged with learning is inspirational. Examples include fieldwork outside the classroom, discussion and interaction with teachers and students, challenging other's ideas and practices, and doing meaningful work that can be implemented in real world settings. Their stories support the teaching practices identified later in this article and reaffirm the notion that students are most excited about learning when they are actively involved in the learning process through discussion, group work, hands-on participation, and applying information outside the classroom. But, it appears that there continues to be a huge chasm between how students like to learn and how instructors teach.

Huba and Freed (2000) suggested that college faculty continue to use the lecture method; unfortunately, the average attention span of college students is 15-20 minutes (Hoover, 2006; Middendorf \& Kalish, 1996). Our own observations of students text messaging, surfing the internet on their laptops, and, in some cases, sleeping in the back rows of lecture halls may be more common than we think. Sax, Keup, Gilmartin, Stolzenberg, and Harper (2002) and Levine and Cureton (1998) wrote that educators rely heavily on lecture and passive methods of learning, whereas students prefer active methods. Doctoral programs typically do not require students to take any pedagogy courses; thus, it follows that professors continue to teach the ways in which they were taught and students continue to be disengaged from what professors are saying.

Lecturing, as a way to deliver information should be one of the tools in the educator's toolbox; however, if it is the only tool, and if the only purpose it serves is to dole out information for the next exam, then student learning may be diminished. Lectures should be used as a method to help students understand theories and ideas, which they can then apply in the world. Students should be able to go out and test information after receiving it to discover whether the ideas and theories learned in the classroom have any value. If they do not apply it in due time, the importance of what was taught may get lost, transformed, or misused.

According to Astin and Oseguera (2002), the national rate of college baccalaureate completion is less than $50 \%$, which may be due in part to the use of passive teaching methods. Levitz, Noel, and Richter (1999) identified multiple reasons why students drop out, which included "experiencing poor or indifferent teaching” (p. 40). They suggested that a cultural change needs to occur in colleges, which includes faculty focusing more attention on students and allowing them more opportunities to actively participate in the classroom.

College students go through a phase called "focused exploration" which is when they experiment with different career possibilities and attempt to determine what they want to do with their lives. Why not conduct our classrooms in a way that embraces this time of life and structures greater exploration around meaningful, educative experiences? Opportunities such as "studying abroad, service learning, cooperative learning, internships, and conducting observations 
outside of school" should be provided at this critical phase in life (Shaller, 2005, p. 21). Unfortunately, Shaller suggested that many students instead find themselves sitting in large lecture halls disengaged from their education.

There are multiple ways to deliver information in classroom settings: lecturing, direct instruction, textbook recitation, cooperative learning, discussion method, problem-based learning, and discovery method to mention a few (Moore, 2009). Some of these delivery methods are more passive and others are more active. Certain methods may appear to be exclusively passive, but may actually include some participation. Lecturing, for example, may include short episodes where students respond to questions raised by the instructor. On the other hand, methods that are viewed as active may be anything but active. For example, very little student participation is necessary in problem-based learning where educators control the process not only by determining what problem to solve, but providing all the information needed to solve the problem as well.

One learning theory that provides direction on how to make learning active is Dewey's (1938) "pattern of inquiry.” Dewey's pattern of inquiry consists of six steps. His explanation of this theory, however, is very similar to the scientific method (pp. 101-119). He explained that a relevant problem causes perplexity and desire to find an answer (step one), which is then followed by creating a plan (step two), testing the plan against reality (step three), and reflecting on its worth (step four). The planning and testing phases of this process are what makes learning active. Responding to instructor questions and reciting back information allow students to talk, but learning becomes active when they create plans to solve problems and test them in real world scenarios. Creating a web site, building a learning portfolio, performing a chemistry experiment, creating a piece of artwork, or building something from a blueprint require students to plan and test ideas to determine their worth. For Dewey, the term "active" indicated learning in ways other than reciting and memorizing information.

Five innovative teaching approaches that attempt to incorporate Dewey's pattern of inquiry are Project-based learning, problem-based learning, service learning, place based education, and active learning. These five approaches are beginning to help us to step outside the confines of traditional education and are creating new learning environments that are changing the way students, educators, administrators and others view learning. These five approaches often promote excitement and enthusiasm in the classroom, and each begins by centering on the student embracing situations where they are in control of what they learn. Underlying principles of all five approaches include: hands-on learning, using a problem solving process, addressing real world problems, encouraging student interaction with each other and the content, engaging in direct experiences, and using multiple subjects to enhance interdisciplinary learning.

These principles are integral to experiential learning and are used in different proportions in the five teaching approaches. For instance, project-based learning has a strong hands-on component because students are using their hands to design and construct things. The end result is a product of some sort. Problembased learning on the other hand, focuses more on having students undergo a problem solving process where students work in small groups discussing and creating a plan to solve a real life problem. Some of these teaching approaches 
may rely more heavily on one principle, whereas alternative approaches rely more heavily on others.

Although these teaching approaches have been implemented with all subject areas, certain ones lend themselves more readily to experiential approaches to learning. Art, science, family and consumer sciences, physical education, and technology education for instance, are more hands-on in nature because students in these disciplines often create art works, perform experiments, bake food, engage in sports activities, and construct things from metal and wood. Subjects that are less apt to use experiential approaches are history, philosophy, and math where the focus tends to be on learning dates, theories, and equations. Problembased learning might be a better method for these classical disciplines because problems can easily be identified and created within each of these subjects. For example, a history problem could focus on key factors of how wars were started and how they could have been prevented; a philosophy problem could focus on ethical case studies and how people decide what is right and wrong; and a math problem could focus on how to use certain math formulas to solve real life problems. Problems can be found everywhere in these subjects; it just take a little creativity to design them so they are relevant to the learners. Using teaching approaches that promote experiential learning is challenging but it is also rewarding, especially when students become motivated self-directed learners.

These teaching approaches have significant bodies of literature devoted to explaining theories and techniques that can help educators create more exciting classrooms by motivating students to learn on their own. There are even professional organizations that host conferences and workshops to help educators integrate these approaches into their schools and classrooms. The amount of attention these approaches are receiving continues to increase and there appears to be a growing movement to use them in both high school and college classrooms. A brief over view of each approach is provided so educators can determine which approach or approaches may best fit their classroom situation, as well as resources on how to implement them into classroom environments.

\section{Five Experiential Approaches}

\section{Project-based Learning}

Project-based learning has been defined as "a teaching method where teachers guide students through a problem solving process which includes identifying a problem, developing a plan, testing the plan against reality, and reflecting on the plan while in the process of designing and completing a project” (Wurdinger, Haar, Hugg, \& Bezon, 2007, p. 151). With this teaching approach students create and produce projects. For instance, students might build a birdhouse, design a web page, or create a learning portfolio. When projects are completed students often present them to their peers with an explanation of how they created the project and what they learned from the experience.

Multiple research studies across North America suggest that Project-based learning helps improve schools because it inspires students to learn and changes their attitudes about school (Blumenfeld et al., 1991; Grant \& Branch, 2005; Levine, 2002; Littky \& Grabelle, 2004; Newell, 2003; Thomas, Enloe, \& Newell, 
2005). Several research studies conducted in other countries have also found that Project-based learning is effective at improving student learning (Barak \& Dori, 2005; Gultekin, 2005).

Minnesota New Country School (MNCS) is one of 40 schools created by EdVisions that uses project-based learning as their primary teaching method (EdVisions, 2008). MNCS has a National reputation for designing their entire curriculum on Project-based learning and places a strong emphasis on selfdirected learning. MNCS's view of success focuses on teaching academic content, as well as important life skills that are needed to be productive members of society.

Students that attend EdVision's schools are given the freedom to determine their own projects and work at their own pace, and the teachers, who are called advisors, act as guides or facilitators of the learning process. Student projects are broad ranging and have included designing museums, developing software programs, designing claymation characters, creating videos, and creating documentaries through pictures (Newell, 2003). Depending upon their complexity, these projects may take a few days or several months to complete. Students demonstrate their work by conducting an exhibition to their advisory group consisting of peers, advisors, community members, and parents when they finish their projects. After the exhibitions, advisors and students discuss what curriculum standards have been met through the project, and how many credits will be received for their work.

In higher education one is more likely to find individual faculty members using Project-based learning, however a few degree programs use it extensively, and in one case Northface University, in Salt Lake City, Utah, has adopted this approach extensively. This university enrolled its first cohort in 2004, and developed a curriculum based entirely on project-based learning. Gonzales and Nelson (2005), through interviews and discussions with educators and students at Northface, discovered that this University's use of Project-based learning has convinced Global 1,000 companies like IBM and Microsoft to create partnerships allowing students to work on enterprise projects within these organizations.

\section{Problem-based Learning}

Problem-based learning focuses on having students undergo a problem solving process and often work together in small groups to find solutions. The roots of problem-based learning stem back to the field of medical education at McMaster University in Ontario, Canada when they began using it in 1969 as an alternative approach to train doctors in analyzing medical problems (Ramsey \& Sorel, 2007). Barrows and Tamblyn (1980), two of the early pioneers of problem-based learning, defined it as "the learning that results from the process of working toward the understanding or resolution of a problem" (p. 18). More recently, it has been defined as a process where "students formulate and pursue their own learning objectives by researching a situation, developing appropriate questions, and producing their own solution to a problem" (Maxwell, Mergendoller, \& Bellisimo, 2005, p. 316). In a science class for example, students could be given a problem on how to save energy in their classroom, in which case they will need to figure out what appliances use energy in the classroom, how much energy is being used by each appliance, and how to cut back on their use. 
According to Woods et al. (1997), students taught with the problem-based learning approach acquire greater problem solving, interpersonal, and life-long skills compared with those taught by more conventional teaching methods; more recent studies found that students increased their learning and leadership skills through participating in problem-based learning courses (Baker, McDaniel, Pesut, \& Fisher, 2007; Maxwell, et al., 2005).

According to Jones (1996) and Vernon and Blake (1993), numerous medical schools are using problem-based learning. In fact, Delisle (1997) stated that 60 medical schools around the world, which include the fields of dentistry, nursing, pharmacy, and optometry, use this approach.

\section{Service Learning}

Service Learning is an approach that blends learning while providing a service to a community. Identifying a need is the first step which is followed by creating an action plan to address this need. "Service Learning can be defined as a teaching method where guided or classroom learning is deepened through service to others in a process that provides structured time for reflection on the service experience and demonstration of the skills and knowledge acquired” (Kaye, 2004, p. 7).

For example, students may see a need to help feed lower income families in their community so they organize a food drive and work with the local food bank to deliver donations to families. Service could include an assignment such as interviewing the manager at the food bank about community needs, and then publishing an article in the local paper. Service assignments often provide greater depth to the learning experience. However, it is important to tie in relevant learning with service in this approach as simply providing a service does not mean that the student takes away any learning.

Service learning increases student achievement and motivation by eliciting real-world connections between book learning and the everyday lives of students (Soslau \& Yost, 2007). By creating a link between school and the community, students become more invested, not only in their schoolwork, but in their community. In fact, the most common reasons cited for the adoption of servicelearning included helping students to become more active members of the community, increasing student knowledge and understanding of the community, meeting real community needs, and encouraging students' altruism and caring for others (Billing, 2000).

Studies show that students who are actively engaged in their own learning take ownership of it and, thus, are more motivated to learn (Soslau \& Yost, 2007). Service learning provides this type of learning environment. California State University Monterey Bay was founded in 1994 as the first comprehensive state university requiring service learning for graduation (Titlebaum, Williamson, Daprano, Baer, \& Brahler, 2004). Many universities are weaving service into their mission statements and formalizing a service-learning component into requirements for graduation. Numerous benefits can be attributed to participating in service learning, including greater self-knowledge, increased personal efficacy, a better ability to work with others, a heightened feeling of being connected to a community and closer ties between students and faculty (Eyler \& Giles, 1999). At Nebraska Methodist College-Josie Harper Campus, the nursing program has an accelerated community-based curriculum for the purpose of 
allowing students opportunities to develop relationships with community members in order to gain an understanding of unique needs within a community (Ward et al., 2007). Other colleges are recognizing service learning as an important component to a well-rounded education. For example, at Bentley College students can work towards a Service Learning Certificate, which is earned in addition to their bachelor's degree and represents to potential employers that social responsibility and ethics are important (Bently College, n.d.).

\section{Place-based Education}

This approach stems from the field of environmental education and focuses on understanding and improving one's immediate environment, or place in which one lives, by using an interdisciplinary approach to education. Sobel (2005) defined it as "the process of using the local community and environment as a starting point to teach concepts in language arts, mathematics, social studies, science, and other subjects across the curriculum. Emphasizing hands-on, real world learning experiences, this approach to education often increases academic achievement, helps students develop stronger ties to their community, enhances students' appreciation for the natural world, and creates a heightened commitment to serving as active, contributing citizens” (p. 7). Learning is rooted in the local community and environment and it may have a service component, although it is not required. For instance, learning about the history of one's community or identifying plants and animals that live in the area are forms of place-based education that do not have a service component. Doing a place-based project to determine the benefits of using natural herbicides like corn gluten over chemical herbicides, for instance, could provide a real service to a city parks department that places fertilizers on green spaces within the community.

At the university level, certain colleges are designing their academic programs around this approach to teaching. Southeast Alaska Tribal College's mission statement mentions that place-based education is a key component to the courses offered at the college. They note: "The tribal college in Southeast Alaska is developing certificate and degree programs founded on principles of placebased education, inspired by and modeled after traditional Tlingit, Haida and Tsimshian ways of knowing” (Southeast Alaska Tribal College, n.d.). There are even graduate programs such as the Master of Fine Arts at Chatham University that focuses on this approach: The heart of our program-nature, environmental and travel writing - honors Carson's legacy, but expands the interpretation of environment to include any place-based writing and all genres-poetry, fiction and creative nonfiction-shaped by human relationship with place (Chatham University, n.d.).

\section{Active Learning}

Bonwell and Eison (1991) provided a simple definition stating that it is "anything that involves students in doing things and thinking about the things they are doing” (p. 2). Meyers and Jones (1993) provided more detail in their definition: "active learning provides opportunities for students to talk and listen, read, write, and reflect as they approach course content through problem-solving exercises, 
informal small groups, simulations, case studies, role playing, and other activities-all of which require students to apply what they are learning” (p. xi). Whether it's a role-play, simulation, debate, or drama the focus of active learning is getting students involved in discussion and reflection on how they might apply what was taught to real life situations. Any technique to get students talking could be considered an active learning technique, but the one technique it does not include is lecturing. These techniques are designed to occur in classrooms where time is limited.

For those that have relied on lecturing as their primary teaching format, this approach may appear rather risky. This approach requires letting go of some control in the classroom and allowing students the freedom to express their ideas which may take a discussion in a direction that was not planned by the instructor. As such, students are more likely to retain information if they are engaged in the learning process.

Bransford, Brown, and Cocking (1999) found that when students are actively engaged in the learning process they are not only able to understand more complex material, but are able to transfer their learning from one problem solving context to another. Their study suggests that active learning promotes problem solving skills, and knowledge transfer. Machemer and Crawford (2007) conducted a study and found that students sometimes prefer memorizing information over active learning, but only in situations when they need to remember the information for a test. When tests and grades are not an issue, they prefer active learning. Unfortunately, the education system has created a situation where knowledge is equated to memorizing information, and the ability to solve problems holds less value.

\section{General Considerations When Using These Five Approaches}

Using teaching approaches that promote experiential learning is challenging but rewarding, especially when students become motivated self-directed learners. With these approaches, educators take a less visible role in the classroom, guiding students through the learning process by encouraging them to take risks and challenging them to learn from their mistakes because that is how human beings learn. Students have more freedom to explore the learning process and the educator's role is to help them when they get stuck so they can keep moving forward with their own learning. Educators are not the center of attention in the classroom, student learning is.

A different type of classroom culture needs to be created when using these teaching approaches. The role of the educators becomes more like a facilitator with the purpose founded in guiding students in designing meaningful learning experiences and allowing them time to complete and demonstrate their comprehension to an audience of peers, when applicable. Students become active participants with these teaching approaches and need to understand that a different culture combined with a set of expectations is a beneficial way to learn. Changing the classroom culture requires a change in the educator's role and the student's role as well as a change in the classroom structure.

With these innovative teaching practices students should not be confined to their chairs. Students need to experience their learning in a less directed way to fully benefit from these teaching methods. To engage in their learning process 
students need autonomy, which may include brainstorming ideas with peers, moving around the classroom to gather resources and using technology to access information. Something as simple as rearranging classroom desks into circles can help change the culture of the classroom.

Another important consideration when using these innovative approaches is that they are not "all or nothing” strategies for classroom engagement. There will be times when certain material needs to be covered and retained by the students. With each of these approaches, educators can have as large or as small of a role during the active phase of learning. For example, in a science class, students could be given the problem of implementing 10 environmental practices to conserve more energy and provide a presentation to the class on these practices. The educators could provide students with a variety of different practices and then ask students to choose and implement these different practices on their own. Presentations allow the educator to assess the learning and provide opportunity for discussing the advantages and disadvantages of each practice.

The most important underlying theme is that through these approaches students become more engaged in learning. Providing opportunities that allow for creativity, direct experience, and personal interpretation will not only engage students in their learning, but promote a more humanistic approach to education. In turn, when a lecture is necessary, students will likely have a better attention span and connect with the material because they have been allowed to experience it on their own terms. Below are a few ideas which educators might want to discuss with students before using these methods.

\section{Educator's Role}

1. The educator will act as a guide allowing students to make mistakes and learn from them along the way.

2. Educators will provide students with freedom to experiment in order to discover solutions to the problems they encounter.

3. The educator will provide students with resources and information when they get stuck so that they can continue moving forward with their learning.

\section{Student's Role}

1. Students will be allowed freedom in the classroom as long as they are moving forward in the learning process.

2. Students may need to undergo a series of trials and errors as they attempt to complete the assignment.

3. Students should understand that the problem solving process becomes as important as the content being learned.

\section{Exhibitions}

Certain charter schools across North America that use experiential approaches rely heavily on exhibitions as a tool to evaluate student learning. The Metropolitan Regional Technical charter high school in Providence, Rhode Island uses exhibitions as an assessment tool. Littky and Grabelle (2004), intricately involved in this school, described exhibitions as "kids getting up and 
talking passionately about a book they've read, a paper they've written, drawings they've made, or even what they know about auto mechanics. It is a way for students to have conversations about the things they have learned” (p. 7). Projectbased charter schools such as the ones created by EdVisions also have their students do exhibitions after completing their projects. They hold exhibitions about every six weeks where the public is invited to the school to listen to students present on their projects. They also have students do a major exhibition after completing their senior projects, which usually require 300 to 400 hours of research. When students do exhibitions they "take their projects more seriously, they get valuable practice speaking in public, the parents better understand the learning process, the public knows the school is serious about academics, and it builds community” (Newell, 2005, p. 14).

College students also enjoy exhibitions because they are opportunities to teach their peers about their own personal experiences with different strategies, techniques, and applications that they have experimented with in their own way. Having students present their work after they complete it helps solidify their learning and should be considered as an assignment when using these teaching approaches. Exhibitions help students organize their thoughts, express their ideas and opinions, and reflect on the important things they have learned during the process. Exhibitions are different than many typical classroom presentations because students are speaking from direct experience, not about abstract theory. Direct experience allows them to comprehend and speak more intelligently about the subject matter because they tested their ideas in a real world setting. An exhibition helps them learn to organize their experience and put it into words that will hopefully be understood by their audience. Once again, the time frame is important to consider as some classroom educators may not be able to afford giving up several class periods in order for students to do exhibitions. But, short ones are better than none at all.

\section{Conclusion}

Typically, lecturing and direct instruction do not include an active phase where students plan and test out information; these approaches, however, could be designed to include some experiential learning. Educators could use lecture in class and create assignments that require students to apply information outside the classroom. Courses could be designed with a combination of passive and active phases where lectures provide the passive learning and application provides the active phase. A better approach would be to provide opportunities in class for students to apply information so that educators are present to guide this phase of the learning process. Unfortunately, many public schools and higher education institutions are structured with short class periods which are not conducive for experiential learning. Limited class time is a barrier. However, it is still possible to integrate small episodes of experiential learning in class, and it is certainly feasible to provide assignments that require students to apply the information outside class time.

Other barriers such as large class numbers and money can also be overcome (Wurdinger, 2005). Large classes can be divided into small groups, and each group can be given problems to solve. Groups can create plans and report back to 
the entire class on their solutions, which allows for experiential learning to occur in large classes.

Materials to build elaborate projects will cost money; however, projects can be designed in such a way where costs will be minimal. Projects can usually be scaled down in size, which reduces the amount of materials needed. Using these approaches requires some creativity on the part of the instructor but there are often ways to overcome them.

The effort to overcome barriers is well worth it because these approaches create exciting learning environments. To make these approaches effective educators need to remember to let go of some control and allow students freedom to learn on their own. Mistakes should be expected as instructors attempt to implement these teaching approaches; however, instructors will grow professionally by experimenting and trying new things in the classroom. Students should be told at the outset of the course that the instructor is using a new approach and that she will be learning along with the students how to best implement the approach. Instructors do not need to have all the correct answers all the time. That is what learning is all about-pursuing questions and problems that you don't have the answers to. Students will appreciate these approaches and will appreciate an honest instructor as the entire class moves forward in discovering answers to the unknown.

\section{References}

Astin, A., \& Oseguera, L. (2002). Degree attainment at American colleges and universities. Los Angeles: University of California, Higher Education Research Institute.

Baker, C. M., McDaniel, A. M., Pesut, D. J., \& Fisher, M. L. (2007). Learning skills profiles of master's students in nursing administration: Assessing the impact of problem-based learning. Nursing Education Perspectives, 28(4), 190-195.

Barak, M., \& Dori, Y. J. (2005). Enhancing undergraduate students' chemistry understanding through project-based learning in an IT environment. Science Education, 89(1), 117-139.

Barrows, H. S., \& Tamblyn, R. H. (1980). Problem-based learning: An approach to medical education. New York: Springer Publishing Company.

Bently College. (n.d.). Service learning certificate. Retrieved November 18, 2007, from http://www. bentley.edu/service-learning/service-learning_certificate.cfm

Billing, S. H. (2000). Research on K-12 school-based service-learning: The evidence builds. Phi Delta Kappan, 81(9), 658-664.

Blumenfeld, P., Soloway, E., Marx, R., Krajcik, J., Guzdial, M., \& Palincsar, A. (1991). Motivating project-based learning: Sustaining the doing, supporting the learning. Educational Psychologist, 26(3/4), 369-398.

Bonwell, C. C., \& Eison, J. A. (1991). Active learning: Creating excitement in the classroom. ASHE-ERIC Higher Education Report No. 1. Washington, DC: The George Washington University, The School of Education and Human Development.

Bransford, J. D., Brown, A. L., \& Cocking, R. R. (Eds.). (1999). How people learn: Brain, mind, experience, and school. Washington, DC: National Academy Press.

Chatham University. (n.d.). Master of Fine Arts in creative writing. Retrieved November 06, 2007, from www.chatham.edu/departments/writing/graduate/writing/

Delisle, R. (1997). How to use problem-based learning in the classroom. Alexandria, VA: Association for Supervision and Curriculum Development.

Dewey, J. (1938). Logic: The theory of inquiry. New York: Holt, Rinehart, and Winston.

EdVisions. (2008). Retrieved September 24, 2008, from edvisions.com/

Eyler, J., \& Giles, D. E. (1999). Where’s the learning in service-learning? San Francisco: JosseyBass. 
Grant, M., \& Branch, R. (2005). Project-based learning in a middle school: Tracing abilities through the artifacts of learning. Journal of Research on Technology in Education, 38(1), 6598.

Gonzales, A. H., \& Nelson, L. M. (2005). Learner centered instruction promotes student success. The Journal, 32(6), 10-15.

Gultekin, M. (2005). The effect of Project-based learning on learning outcomes in the $5^{\text {th }}$ grade social studies course in primary education. EDAM, 5(2), 519 -556.

Hoover, S. (2006). Popular culture in the classroom: Using video clips to enhance survey classes. History Teacher, 39(4), 467-478.

Huba, M. E., \& Freed, J. E. (2000). Learner-centered assessment on college campuses: Shifting the focus from teaching to learning. Needham Heights, MA: Allyn \& Bacon.

Jones, B. F., Rasmussen, C. M., \& Moffit, M. C. (1996). Real life problem solving: A collaborative approach to interdisciplinary learning. Washington, DC: American Psychological Association.

Kaye, C. B. (2004). The complete guide to service learning. Minneapolis, MN: Free Spirit Publishing.

Levine, E. (2002). One kid at a time: Big lessons from a small school. New York: Teachers College Press.

Levine, A., \& Cureton, J. S. (1998). When hope and fear collide: A portrait of today's college student. San Francisco: Jossey-Bass.

Levitz, R., Noel, L., \& Richter, B. (1999). Strategic moves for retention success. New Directions for Higher Education, 27(4), 31-49.

Littky, D., \& Grabelle, S. (2004). The big picture: Education is everyone's business. Alexandria, VA: Association for Supervision and Curriculum Development.

Machemer, P. L., \& Crawford, P. (2007). Student perceptions of active learning in a large crossdisciplinary classroom. Active Learning in Higher Education, 8(1), 9-30.

Maxwell, N. L., Mergendoller, J. R., \& Bellisimo, Y. (2005). Problem-based learning and high school economics: A comparative study of instructional methods. Journal of Economic Education, 36(4), 315-331.

Meyers, C., \& Jones, T. B. (1993). Promoting active learning: Strategies for the college classroom. San Francisco: Jossey-Bass.

Middendorf, J., \& Kalish, A. (1996). The change up in lectures. The National Teaching and Learning Forum, Retrieved February 28, 2009, from www.ntlf.com/html/pi/9601/article1.htm

Moore, K. D. (2009). Effective instructional strategies. Los Angeles: Sage Publications.

Newell, R. (2005). Student ownership: Teacher ownership. In D. Thomas, W. Enloe, \& R. Newell (Eds.), The coolest school in America: How small learning communities are changing everything (pp. 19-27). Lanham, MD: Rowman and Littlefield Publishers.

Newell, R. (2003). Passion for learning: How Project-based learning meets the needs of 21stcentury students. Lanham, MD: The Scarecrow Press.

Ramsey, J., \& Sorel, E. (2007). Problem-based learning: An adult-education-oriented training approach for SH \& E practitioners. Professional Safety: American Society of Safety Engineers. September, 41-46.

Sax, L. J., Keup, J. R., Gilmartin, S. K., Stolzenberg, E. B., \& Harper, C. (2002). Findings from the 2000 administration of 'Your First College Year': National aggregates. Los Angeles: University of California, Higher Education Research Institute.

Shaller, M. (2005). Wandering and wondering: Traversing the uneven terrain of the second college year. About Campus, July-August.

Sobel, D. (2005). Place-based education: Connecting classrooms and communities ( ${ }^{\text {nd }}$ ed.). Barrington, MA: The Orion Society.

Soslau, E., \& Yost, D. (2007). Urban service-learning: An authentic teaching strategy to deliver a standards-driven curriculum. Journal of Experiential Education, 30(1), 36-53.

Southeast Alaska Tribal College. (n.d.) Science technology, engineering and math: Prospectus for planned programs. Retrieved November 6, 2007, from www.ankn.uaf.edu/NPE/TribalColleges/SEATC/STEM.html 
Thomas, D., Enloe, W., \& Newell, R. (2005). The coolest school in America. Lanham, MD: Scarecrow Education.

Titlebaum, P., Williamson, G., Daprano, C., Baer, J., \& Brahler, J. (2004). Annotated history of service learning. Retrieved November 20, 2007, from http://www.servicelearning.org/filemanager/ download/142/SL\%20Comp\%20Timeline\%20315-04_rev.pdf

Vernon, D. T., \& Blake, R. L. (1993). Does problem-based learning work? A meta-analysis of evaluation research. Academic Medicine, 68, 550-563.

Ward, S., Blair, M., Henton, F., Jackson, H., Landolt, T., \& Mattson, K. (2007). Service learning across an accelerated curriculum. Journal of Nursing Education, 46(9), 427-430.

Woods, D. R., Andrew, N., Hrymak, A. N., Marshall, R. R., Wood, P. E., \& Crowe, C. M. (1997). Developing problem-solving skills: The McMaster problem solving program. Journal of Engineering Education, 86(2), 75-91.

Wurdinger, S., Haar, J., Hugg, B., \& Bezon, J. (2007). A qualitative study using Project-based learning in a mainstream middle school. Improving Schools, 10(2), 150-161.

Wurdinger, S. D. (2005). Using experiential learning in the classroom: practical ideas for all educators. Lanham, MD: Scarecrow Education. 